\title{
Ultrasound ionization of biomolecules
}

\author{
Chen-I Wu ${ }^{1}$, Yi-Sheng Wang ${ }^{1}$, Nelson G. Chen ${ }^{2}$, Chung-Yi Wu ${ }^{1}$ and Chung-Hsuan Chen ${ }^{1 *}$ \\ ${ }^{1}$ The Genomics Research Center, Academia Sinica, Taipei, Taiwan, Republic of China \\ ${ }^{2}$ Department of Biomedical Engineering, University of Michigan, Ann Arbor, MI, USA
}

Received 15 April 2010; Revised 21 June 2010; Accepted 24 June 2010

\begin{abstract}
To date, mass spectrometric analysis of biomolecules has been primarily performed with either matrix-assisted laser desorption/ionization (MALDI) or electrospray ionization (ESI). In this work, ultrasound produced by a simple piezoelectric device is shown as an alternative method for soft ionization of biomolecules. Precursor ions of proteins, saccharides and fatty acids showed little fragmentation. Cavitation is considered as a primary mechanism for the ionization of biomolecules. Copyright (C) 2010 John Wiley \& Sons, Ltd.
\end{abstract}

Matrix-assisted laser desorption/ionization (MALDI) ${ }^{1-4}$ and electrospray ionization (ESI) ${ }^{5-7}$ are two major methods for mass analysis of biomolecules and organic polymers. MALDI requires an expensive pulsed laser to achieve desorption and ionization, while ESI requires a high voltage on the tip of the spray to extract solvated ions. In addition to MALDI and ESI, laser-induced acoustic desorption (LIAD) has been developed for detection of biomolecules and cells. ${ }^{8-11}$ LIAD has also been used for molecular desorption followed with subsequent ionization processes. ${ }^{12}$ Unlike MALDI and LIAD, ultrasound ionization does not require a laser. Ultrasound ionization also does not require a capillary with high voltage and a spray source which are necessary in a typical ESI device.

In the past, there have been very few reports, if any, on the use of ultrasound for ionization in mass spectrometry applications. Sonic spray ionization (SSI) was developed to obtain ionization of molecules. ${ }^{12-18}$ In SSI, a solution from a capillary is sprayed with a sonic gas flow coaxially to the capillary. The optimum amount of ions is produced at a sonic velocity. In SSI, charged droplets are produced by the highvelocity gas flow. No ionization is observed when the molecular speed is too low and the gas flow rate is less than $1 \mathrm{~L} / \mathrm{min}^{19}$ Charged droplet formation from SSI was explained by Hirabayashi et al. based on the non-uniformity of positive and negative ion concentration distributions near the solution surface. ${ }^{19,20}$ Therefore, non-polar compounds such as benzene are not expected to be observed with SSI. Recently, electrosonic spray ionization (ESSI), which combines traditional ESI with supersonic nebulizing gas, was developed for studying protein folding. ${ }^{21}$ Desorption sonic spray ionization (DeSSI), which couples SSI and desorption electrospray ionization (DESI) ${ }^{22}$ to produce ionization of solid analytes, was also successfully developed..$^{23}$ Recently, Dixon et al. reported the use of radiofrequency acoustic desorption of peptides and the desorbed peptides were

*Correspondence to: C.-H. Chen, The Genomics Research Center, Academia Sinica, 128 Academia Road, Sec.2, Nankang, Taipei, Taiwan.

E-mail: winschen@gate.sinica.edu.tw subsequently ionized by ESI. ${ }^{24}$ To date, ultrasound has only been used to eject charged droplets from micro-machined array devices for mass spectrometry applications. ${ }^{25,26}$

Ultrasound has been broadly used in medical imaging for disease diagnosis ${ }^{27-29}$ and other industrial applications. ${ }^{30,31}$ Many of these applications involve the process of cavitation, a phenomenon in which bubbles form in a region where the pressure of the liquid falls below its vapor pressure. These low-pressure bubbles begin to collapse due to the high pressure of the surrounding medium. As the bubbles collapse, the pressure and temperature increase dramatically. The physical process of cavitation is similar to the boiling process except for the thermodynamic paths that precede the vapor formation. Boiling occurs when the local liquid vapor pressure rises above the ambient pressure. Cavitation occurs when the local pressure falls sufficiently below the saturated vapor pressure. When the bubble collapses, the gas within the bubble dissipates into the surrounding liquid to release a significant amount of energy. Therefore, chemical reactions and even ionization can occur by cavitation. However, ionization seldom occurs in the process of boiling. Using ultrasound to produce cavitation, which can lead to sonoluminescence, was first reported in 1934 by Frenzel and Schultes. ${ }^{32}$ Diedrich et al. observed cavitation-induced polymerization of substituted benzene in $1972 .{ }^{33}$ On the other hand, ionization of benzene by SSI has never been reported. More recently, cavity-induced polymer reactions in high-pressure carbon dioxide under a mild acoustic intensity $\left(\sim 125 \mathrm{~W} / \mathrm{cm}^{2}\right)$ were reported by Kuijpers et al. ${ }^{34}$ Therefore, the phenomenon of cavitation-induced chemical reactions has been established. Didenko and Suslick ${ }^{35}$ demonstrated the production of photon, radicals and ions with a single-bubble cavitation experiment. During the past few years, extensive studies of fusion due to bubble burst sonoluminescence have been pursued. ${ }^{36-39}$ However, no definite conclusion on the occurrence of fusion has been reached. One of the major factors in determining the possibility of bubble fusion is the estimated temperature of sonoluminescence. In 2005, Flannigan and Suslick ${ }^{40}$ observed plasma during single-bubble sonoluminescence. 
They observed atomic Ar emission and ionic $\mathrm{O}_{2}^{+}$and concluded that these species must be produced from a hot plasma core. Storey and Szeri $^{41}$ performed theoretical calculations and estimated the temperature inside the bubble to be $\sim 7000 \mathrm{~K}$. Flint and Suslick ${ }^{42}$ estimated the temperature of cavitation of silicone oil as $\sim 5000 \mathrm{~K}$ by measurement of the Swan band transition. Most temperature estimates of cavitation are based on the Rayleigh-Plesset equation. ${ }^{43}$ Putterman et al. ${ }^{44}$ considered sonoluminescence can result from bremsstrahlung from thermally ionized plasma, which would agree with the experimental results from Flannigan and Suslick. ${ }^{40}$ It appears that ionization by cavitation can definitely occur. In this work, we observed intact biomolecular ions with a piezoelectric process that induced ultrasound. In addition to reporting the mass spectra of biomolecular samples, we also hypothesize a possible ionization mechanism for biomolecules by cavitation.

\section{EXPERIMENTAL}

A simple piezoelectric device (Eleceram Technology Co., Taiwan; model: NUTD25F1630R-SB, electric power: $40 \mathrm{~W}$ ) was used to produce ultrasound. The output ultrasound power was monitored by a broad-band probe hydrophone (RESON Inc., CA, USA; model: TC4038). The typical ultrasound power used for this work was $\sim 4 \mathrm{~W}$. The frequency was measured as $1.7 \mathrm{MHz}$. Solution samples were directly placed on the surface of the piezoelectric device. According to the manufacturer's specifications, small droplets with an estimated size of $1-3 \mu \mathrm{m}$ should be produced. These small droplets were introduced by a capillary into an ion trap mass spectrometer for analysis. The schematic of the device is shown in Fig. 1. There were no nitrogen bubbles throughout the solution samples, and there was no high voltage on the tip of the capillary. No ionization signals were observed prior to a high rate of cavitation, which was visible to the naked eye. Most samples were prepared with biomolecule concentrations of 0.01 to 1 nanomoles $/ \mu \mathrm{L}$ and a couple of microliters of the sample were placed on the surface of the piezoelectric device to produce ionization for mass spectrometric detection.

\section{RESULTS AND DISCUSSION}

Successful ultrasound ionization of proteins, saccharides, and lipids was observed. Mass spectra of angiotensin, insulin A \& B and cholic acid are shown in Fig. 2 as examples. Both positive and negative ions from peptides were also observed. In order to assure no ESI mechanism contributed to signals, spectra were also obtained with different voltages applied to the capillary and no significant differences were found. Therefore, the mechanism of ionization by ultrasound should be different from that of ESI. Based on signal-tonoise $(\mathrm{S} / \mathrm{N})$ ratio, the detection limit for small proteins such as angiotensin and insulin can reach to a few picomoles (pmol). For cholic acid, the detection limit is about 20 pmol. Experiments on different concentrations of angiotensin from $10-1000 \mathrm{pmol} / \mu \mathrm{L}$ were also pursued. The approximate linear relationship of angiotensin ion signals vs. the analyte quantity is shown in Fig. 2(e). With the concentration at $10 \mathrm{pmol} / \mu \mathrm{L}$, the $\mathrm{S} / \mathrm{N}$ ratio was obtained as $\sim 4$. This result agrees with the estimate by $\mathrm{S} / \mathrm{N}$ for the analyte concentration at $1000 \mathrm{pmol} / \mu \mathrm{L}$ from Fig. 2(a). The percentage of sample ionized by ultrasound is expected to be high due to the high energy released by cavitation. Nevertheless, this work was not optimized for detection sensitivity and most ions produced were probably not introduced into the entrance tip of the mass spectrometer; however, the ultimate detection limit could be in femtomole region which should be comparable to the sensitivity by ESI if ultrasound-induced ionization was produced in a device more like the commercial ESI mass spectrometer. Since no voltage is applied, the introduction of ions into the mass analyzer is mostly due to pressure differences and gas hydrodynamics. We chose not to apply a voltage in order to prevent any risk of ionization from an electrospray process.

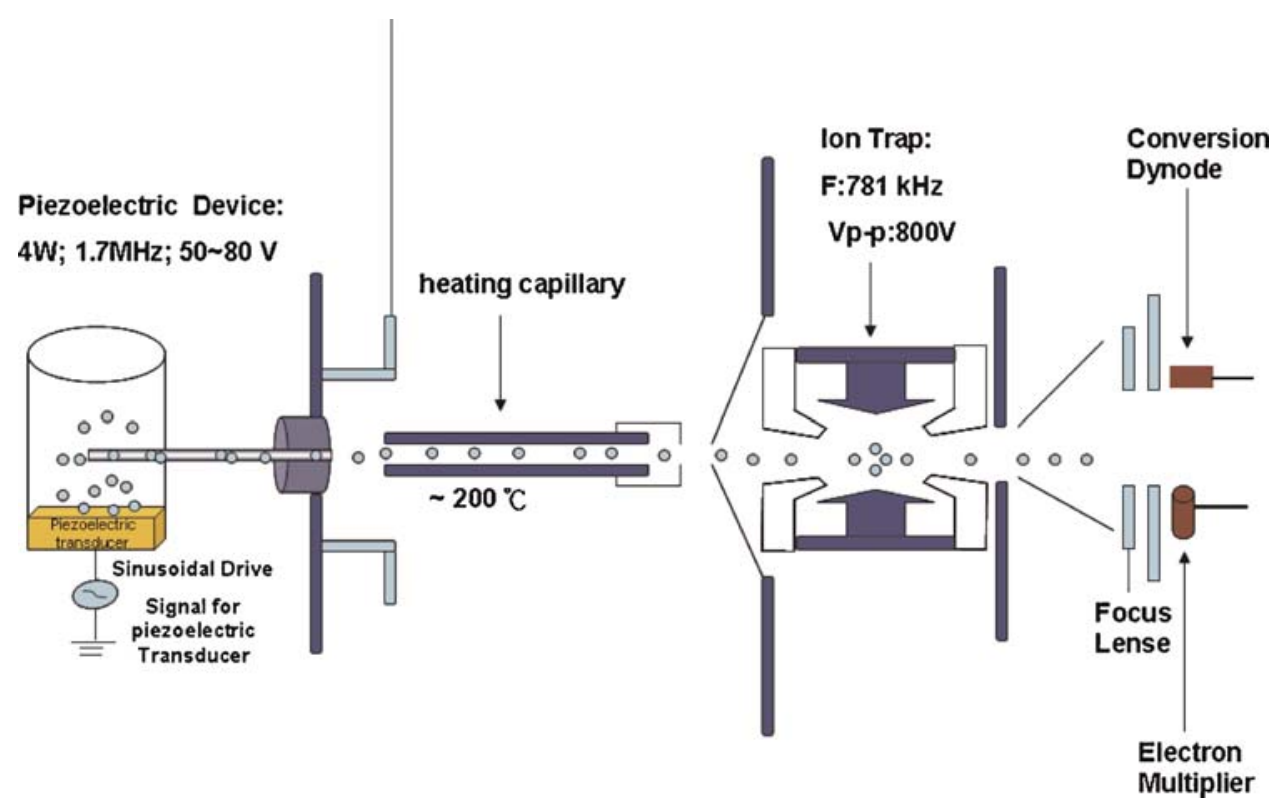

Figure 1. Experimental schematic. 

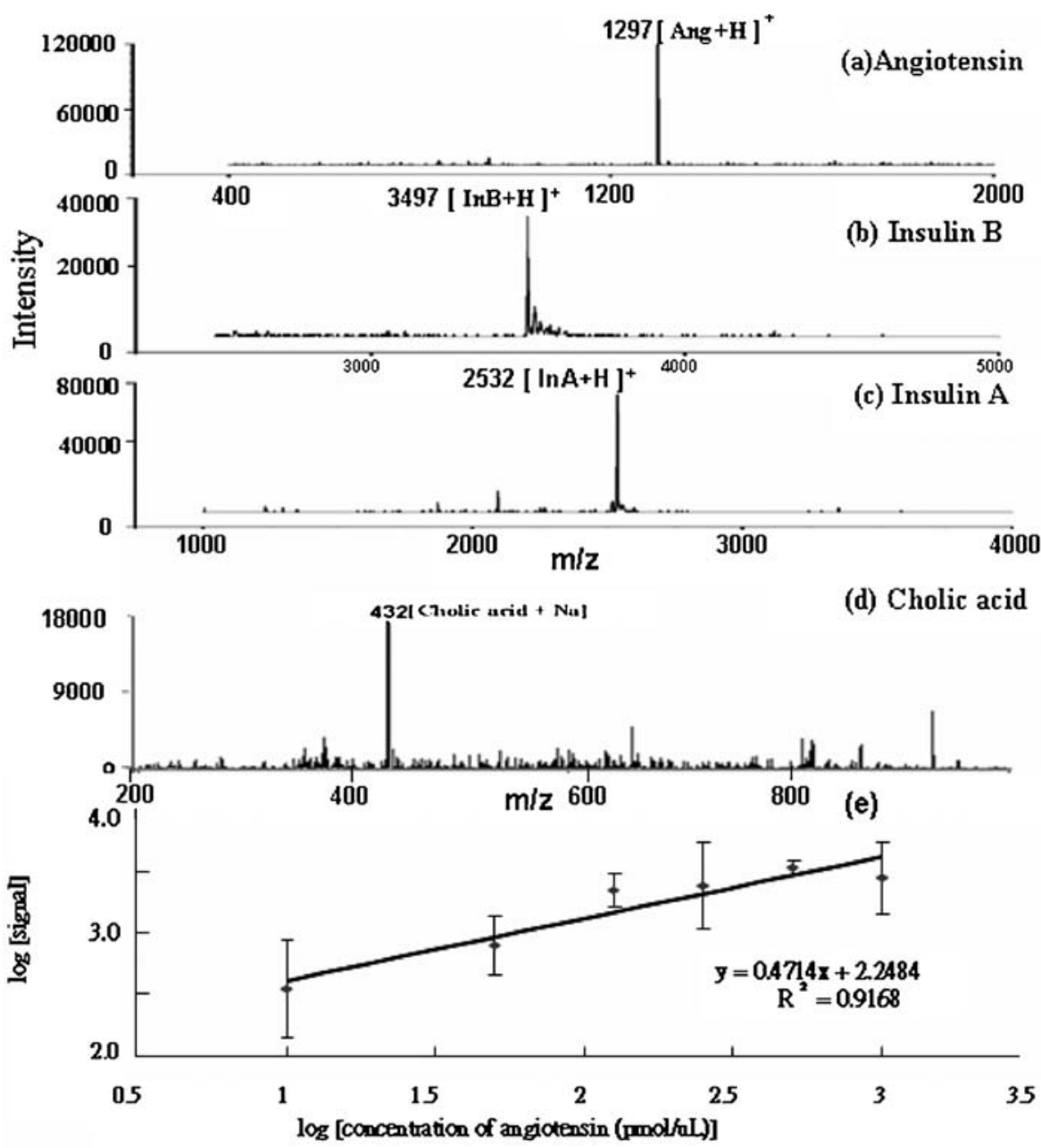

Figure 2. Mass spectra of various samples dissolved in water by ultrasound-induced ionization. Under $4 \mathrm{~W}$ of ultrasound power, mass spectra of (a) angiotensin, (b) insulin $B$, (c) insulin A, and (d) cholic acid are obtained by ultrasound ionization mass spectrometry. A volume of $1 \mu \mathrm{L}$ of sample solution was placed on the surface of the piezoelectric device for analysis. The signal-to-noise $(\mathrm{S} / \mathrm{N})$ ratios for angiotensin, insulin B, insulin A and cholic acid are estimated as 300, 150, 200 and 50, respectively. Insulin A represents insulin chain A from bovine pancreas $(M W=2531.6)$. Insulin chain $B$ is also from bovine pancreas ( $M W=3495.9)$. The linear relationship of signals vs. angiotensin concentration is shown in (e). This indicates that a few picomoles of angiotensin in $1 \mu \mathrm{L}$ can be clearly detected.

Ultrasound ionization was also used to ionize various oligosaccharides. Figure 3 shows the mass spectra of N-linked high-mannose-type oligosaccharide mannose 8 derivative (Man8; chemical formula: $\mathrm{C}_{53} \mathrm{H}_{93} \mathrm{NO}_{41}$; molecular weight (MW): 1400.3). ${ }^{45-47}$ No clear signals were observed for Man8 in aqueous solution. When 2,5 dihydroxybenzoic acid (DHB), trihydroxyacetophenone (THAP), or sinapinic acid (SA) was added, protonated precursor ions were observed. DHB, THAP and SA are known as good matrices for proteins and oligosaccharides with MALDI. Ionization enhancement can be due to the higher acidity of these compounds. However, stronger acids such as hydrochloric acid $(\mathrm{HCl})$ and trifluroacetic acid (TFA) were tested and no clear changes in analyte signals were observed. This indicates the enhancement may be due to the protonation reaction during the cavitation process. In general, many more alkali-attached oligosaccharide ions are produced than protonated oligosaccharides by either MALDI or ESI. With ultrasound-induced ionization, most ions produced are protonated oligosaccharide ions that make spectra analysis much simpler.

In this work, we observed intact biomolecular ions with an ultrasound excitation process. With a piezoelectric device used to produce ultrasound, energy dissipation is primarily through heat transfer and cavitation. The temperature of the sample was between 60 and $100^{\circ} \mathrm{C}$, which was too low to produce ionization. On the other hand, cavitation during the bubble burst process can produce pressures higher than $5 \mathrm{MPa}$ and temperatures reaching $10000^{\circ} \mathrm{C} .{ }^{34}$ Mass spectra of angiotensin samples in various solutions produced by an ultrasound-induced ionization ion trap mass spectrometer are shown in Fig. 4. Signals for biomolecular ions are 
(a)

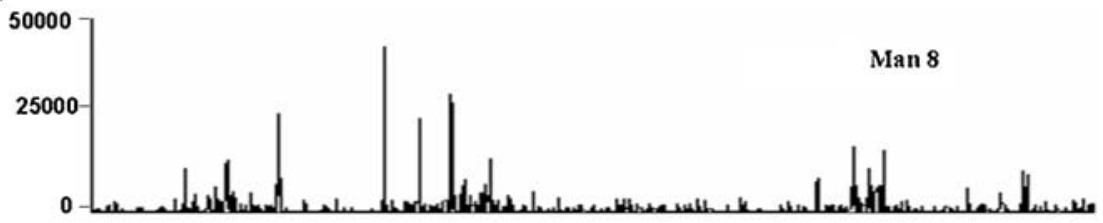

(b)

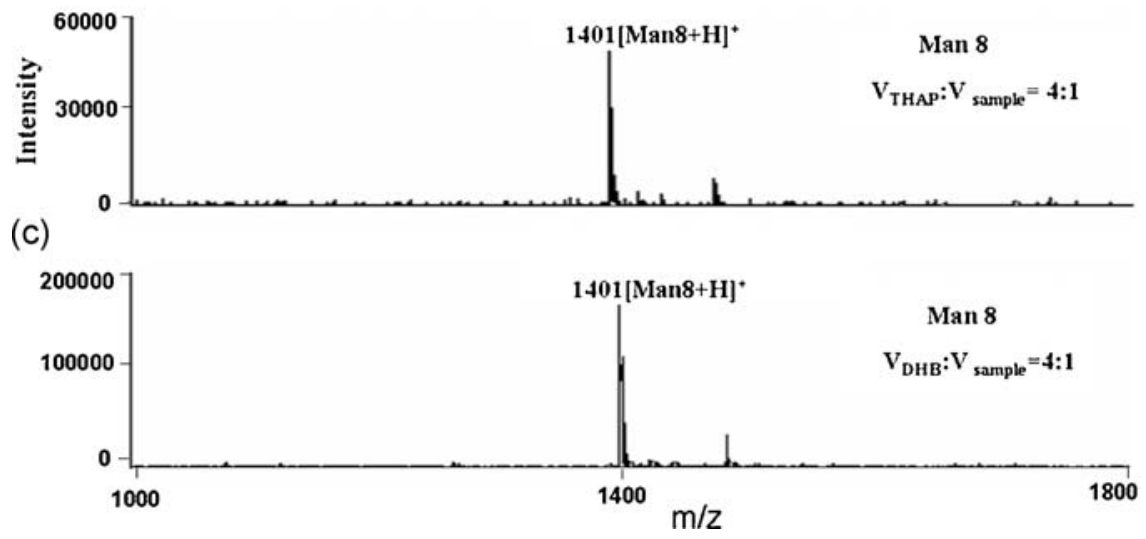

Figure 3. Mass spectra of Man 8. Samples were dissolved in various solutions with the same concentration of $1000 \mathrm{pmol} / \mu \mathrm{L}$. (a) Distilled water, (b) $V_{\text {water }} / V_{\text {THAP }}=1: 1$ and the concentration of THAP matrix is $1000 \mathrm{pmol} / \mu \mathrm{L}$; (c) $\mathrm{V}_{\text {water }} / \mathrm{V}_{\mathrm{DHB}}=1: 1$ and the concentration of DHB matrix is $1000 \mathrm{pmol} / \mu \mathrm{L}$.

increased by a factor of 3 when a mixture of acetone and water was used instead of a pure water solvent. Since the density and viscosity of acetone are lower than those of water, it is easier for cavitation to occur in acetone than in water. ${ }^{35}$ In addition, biomolecule protonation requires significantly more energy in water than in acetone. ${ }^{48}$ Therefore, more ionization can be achieved and more protonated biomolecular ions can be observed with the addition of acetone. No other solvents have been tested but similar effects can be expected for solvents easier to produce cavitation. Both singly and doubly charged ions are obtained in Fig. 4. Since singly charged ion peaks are often dominant, it makes the mass spectra more similar to those from MALDI. The identification of compounds can be conveniently achieved.

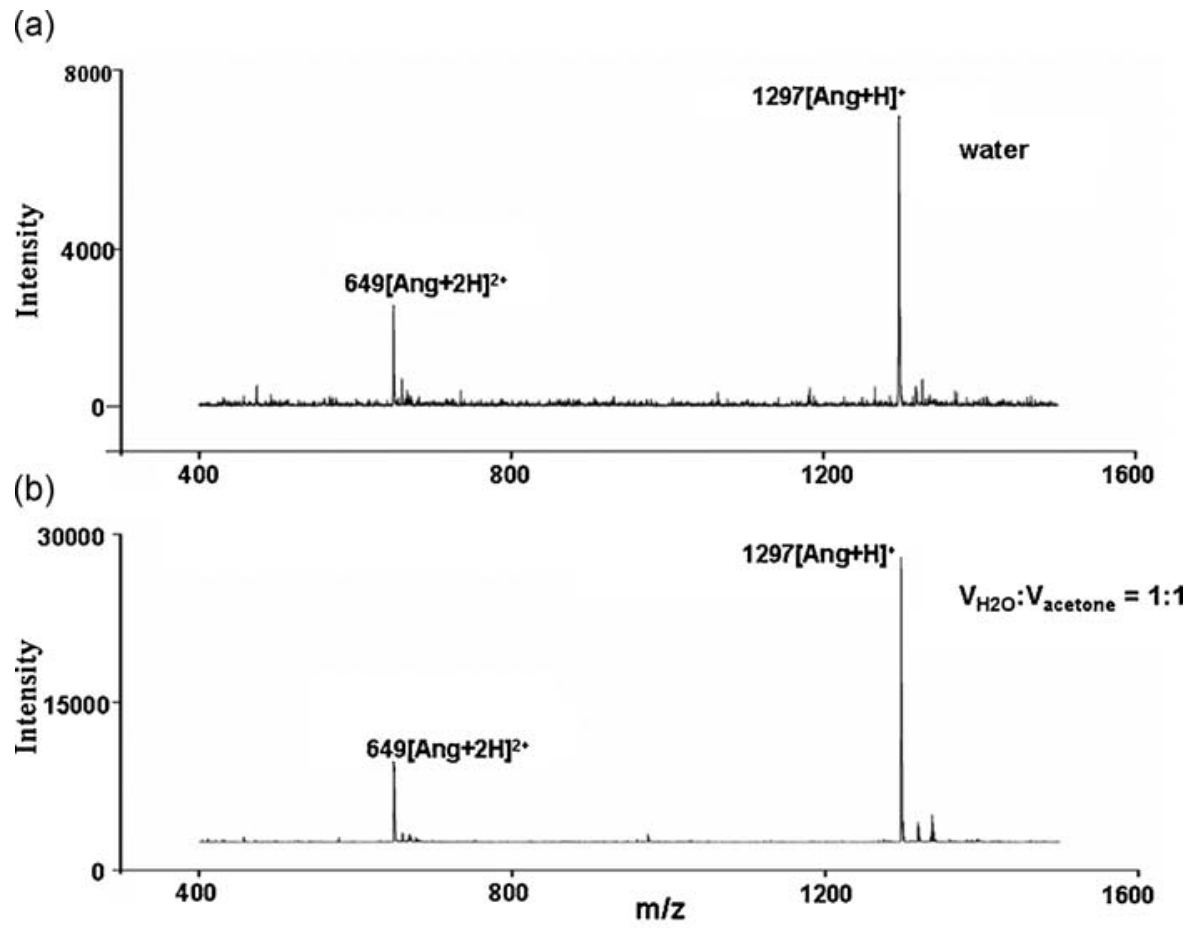

Figure 4. Mass spectra of angiotensin with a concentration of $1000 \mathrm{pmol} / \mu \mathrm{L}$ dissolved in (a) distilled water and (b) $\mathrm{V}_{\text {water }} / \mathrm{V}_{\text {acetone }}=1: 1$. 
SSI does involve sonic expansion to achieve ionization. Nevertheless, the ionization in this work is very different from SSI. In our experiments, SSI could not be achieved since high gas flow was never applied. In addition, SSI needs a capillary for spray. In this work, no capillary spray was used, meaning that the ionization observed could not have come from the SSI process. Furthermore, the size of droplets from SSI is usually less than 1 micron $^{49,50}$ and decreases with increasing gas flow. In our work, the average size of the droplets produced by ultrasound was larger than 1 micron, which is another indication that ionization by ultrasound in this work is not due to SSI. We propose that ionization is likely due to cavitation. We also tested the same samples for ionization due to boiling, but no biomolecular ions were observed. No biomolecular ions were detected when few or no bubbles were produced, even when ultrasound was applied. Since SSI is not expected to ionize non-polar compounds such as polysaccharides, this is another indication that ultrasound-induced ionization is not from an SSI process.

We consider the ultrasound ionization may include the following major steps: (1) Biomolecules are included in the bubble during the bubble formation process. (2) Most energy released at the beginning of the bubble burst is absorbed by water molecules and causes them to ionize and/or dissociate. With the molar ratio of water to biomolecule solute higher than $10^{10}$ to 1 , few biomolecules are fragmented during the cavitation. (3) Protonation and/or deprotonation can occur between water and biomolecules through ion/molecular reactions to produce biomolecular ions. Since the amount of water molecules is at least six orders of magnitude more than the amount of the impurity level of alkali metal ions, more protonation than alkalization can be expected. Therefore, protonated ions are more likely to be observed than alkali atom attached ions.

Since ultrasound-induced ionization was studied in liquid samples, there were no matrix effects due to crystallization, such as sweet spots in MALDI. Nevertheless, mass spectra obtained from ultrasound ionization were dominated by singly charged ions. Therefore, ultrasound ionization compared to MALDI should have the advantage of no sweet spot effect. However, some matrix molecules can enhance ultrasound ionization (Fig. 3). The effect of impurities such as salts was found less important than in ESI. Few sodium-attached polysaccharide ions were detected, even after adding tenfold more $\mathrm{NaCl}$ than polysaccharide into the sample. The piezoelectric ultrasound source is inexpensive, rugged and stable. Therefore, ultrasound ionization is a very simple and convenient method to produce biomolecular ions for mass spectrometric analysis. Up to now, it has been very difficult to obtain mass spectra for water-insoluble compounds such as synthetic organic polymers $^{51}$ by either MALDI or ESI. Since ultrasound ionization is considered to be due to the cavitation process, ionization can possibly occur for non-polar and waterinsoluble organic compounds. By using a frequency scan ion trap mass spectrometer for high $\mathrm{m} / \mathrm{z}$ measurement, ${ }^{52,53}$ ultrasound ionization can have the potential to detect large synthetic water-insoluble organic polymers.

\section{Acknowledgements}

Funding was provided by the Genomics Research Center, Academia Sinica. We thank Prof. Yuan T. Lee for valuable suggestions and K. J. Cherry Lin for help in paper submission.

\section{REFERENCES}

1. Karas M, Bachmann D, Hillenkamp F. Int. J. Mass Spectrom. Ion. Processes 1987; 78: 53.

2. Tanaka K, Waki H, Ido Y, Akita S, Yoshida Y, Yoshida T. Rapid Commun. Mass Spectrom. 1988; 2: 151.

3. Karas M, Hillenkamp F. Anal. Chem. 1988; 60: 2299.

4. Berkenkamp S, Kirpekar F, Hillenkamp F. Science 1998; 281: 260.

5. Wong SF, Meng CK, Fenn JB. J. Phys. Chem. 1988; 92: 546.

6. Henzel WJ, Billeci TM, Stults JT, Wong SC, Grimlec C, Watanabe C., Proc. Natl. Acad. Sci. USA 1993; 90: 5011.

7. Tabb DL, McDonald WH, Yates, JR III. J. Proteome Res. 2002; 1: 21.

8. Golovlev VV, Allman SL, Garrett WR, Taranenko NI, Chen CH. Int. J. Mass Spectrom. Ion Processes 1997; 169/170: 69.

9. Golovlev VV, Lee SSH, Allman SL, Taranenko NI, Chen CH. Anal. Chem. 2001; 73: 809.

10. Peng WP, Yang YC, Kang MW, Tzeng YK, Nie Z, Chang HC, Chang W, Chen CH. Angew. Chem. Int. 2006; 45: 1423.

11. Peng WP, Lin HC, Chu ML, Yu LT, Chang HC, Chen $\mathrm{CH}$. Angew. Chem. Int. 2007; 46: 3865.

12. Campbell JL, Fiddler MN, Crawford KE, Gqamana PP, Kenttamaa HI. Anal. Chem. 2005; 77: 4020.

13. Banks F, Shen S, Whitehouse CM, Fenn F. Anal. Chem. 1994; 66: 406.

14. Hirabayashi Y, Hirabayashi A, Takada Y, Sakairi M, Koizumi H. Anal. Chem. 1998; 70: 1882.

15. Huang M, Kojima H, Hirabayashi A, Koizumi H. Anal. Sci. 1999; 15: 265.

16. Hirabayashi Y, Hirabayashi A. J. Mass. Spectrom. Soc. Jpn. 2002; 50: 21.

17. Takats Z, Nanita SC, Cooks RG, Schlosser G, Vekey K. Anal. Chem. 2003; 75: 1514.

18. Gardner JS, Harrison RG, Lamb JD, Dearden DV. New J. Chem. 2006; 30: 1276.

19. Hirabayashi A, Sakairi M, Koizumi H. Anal. Chem. 1995; 67: 2878.

20. Hirabayashi A. J. Mass Spectrom. Soc. Jpn. 1999; 47: 289.

21. Takats Z, Wiseman JM, Gologan B, Cooks RG. Anal. Chem. 2004; 76: 4050.

22. Cooks RG, Ouyang Z, Takats Z, Wiseman JM. Science 2006; 311: 1566.

23. Haddad R, Sparrapan R, Eberlin MN. Rapid Commun. Mass Spectrom. 2006; 20: 2901.

24. Dixon RB, Sampson JS, Muddiman D. J. Am. Soc. Mass Spectrom. 2009; 20: 597.

25. Aderogba S, Meacham JM, Degertekin FL, Fedorov AG, Femandez FM. Appl. Phys. Lett. 2005; 86: 203110.

26. Hampton CY, Forbes TP, Varady MV, Meacham JM, Fedorov AG, Degertekin FL, Femandez FM. Anal. Chem. 2007; 79: 8154 .

27. Klibanov AL. Adv. Drug Deliv. Rev. 1999; 37: 139.

28. Lindner JR. Nat. Rev. Drug Discov. 2004; 3: 527.

29. Takalkar AM, Klibanov AL, Raychak JJ, Lindner JR, Ley K. J. Contr. Release 2004; 96: 473.

30. van Leeuwen J, Akin B, Khanal SK, Sung S, Grewell D, van Leeuwen JH. Water Sci. Technol. 2006; 6: 35.

31. Oie S, Masumoto N, Hironaga K, Koshiro A, Kamiya A. Microbios 1992; 72: 292.

32. Frenzel H, Schultes HZ. Phys. Chem. 1934; B27: 421.

33. Diedrich GK, Kruus P, Rachlis LM. Can. J. Chem. 1972; 50: 1743.

34. Kuijpers MWA, van Eck D, Kemmere MF, Keurentjes JFT. Science 2002; 298: 1969.

35. Didenko YT, Suslick KS. Nature 2002; 418: 394.

36. Taleyarkhan RD, West CD, Cho JS, Lahey RT Jr, Nigmatulin RI, Block RC. Science 2002; 295: 1868.

37. Shapira D, Saltmarsh M. Phys. Rev. Lett. 2002; 89: 104302.

38. Taleyarkhan RP, Cho JS, West CD, Lahey RT Jr, Nigmutulin RI, Block RC. Phys. Rev. E 2004; 69: 036109.

39. Taleyarkhan RP, West CD, Lahey RT Jr, Nigmatulin RI, Block RC, Xu Y. Phys. Rev. Lett. 2006; 96: 034301. 
40. Flannigan DJ, Suslick KS. Nature 2005; 434: 52

41. Storey BD, Szeri A. J. Proc. Roy. Soc. Lond. A 2000; 456: 1685.

42. Flint EB, Suslick KS. Science 1991; 253: 1397.

43. Hilgenfeldt S, Glossman S, Lohse D. Nature 1999; 398: 402.

44. Putterman S, Evans PG, Vazquez G, Weninger K. Nature 2001; 409: 782 .

45. Caupin F, Herbert ECR. Physique 2006; 7: 1000.

46. Makowski M, Makowska J, Chmurzynski LJ. Mol. Struct: Theorem 2004; 674: 61.

47. Gogate PR, Pandit AB. Utrasonic Sonochemistry 2005; 12: 21
48. Ngyuen MT, Chandra AK, Zeegers-Huyskens TJ. Chem. Soc Faraday Trans. 1998; 94: 1277.

49. The Encyclopedia of Mass Spectrometry, vol. 7, Gross ML, Caprioli RM (eds). Elsevier: Amsterdam, 2007; 487-494.

50. Blakley CR, Vestal ML. Anal. Chem. 1983; 55: 750.

51. Lin T, Lin SY, Lee SL, Chen CH, Hsu CH, Hwang LP, Xie ZY, Chen CH, Hwang SL, Yang HC, Luh YT. Angew. Chem. Int. Ed. 2007; 46: 4481.

52. Peng WP, Yang YC, Kang MW, Tzeng YK, Nie Z, Chang HC, Chang W, Chen CH. Angew. Chem. Int. Ed. 2006; 45: 1423.

53. Peng WP, Lin HC, Chu ML, Yu LT, Chang HC, Chen $\mathrm{CH}$. Angew. Chem. Int. Ed. 2007; 46: 3865. 